\title{
PENGARUH ONLINE BEHAVIOURAL ADVERTISING DAN CONSUMER TRUST PADA SIKAP DAN NIAT KONSUMEN MERESPON ONLINE ADVERTISING
}

\author{
Husin Komar ${ }^{1}$, Hetty Karunia Tunjungsari ${ }^{2}$ \\ ${ }^{1}$ Magister Manajemen, Universitas Tarumanagara Jakarta \\ Email: husinhu88@yahoo.com \\ ${ }^{2}$ Magister Manajemen, Universitas Tarumanagara Jakarta \\ Email: hetty@fe.untar.ac.id
}

Masuk : 31-03-2019, revisi: 01-08-2019, diterima untuk diterbitkan :09-08-2019

\begin{abstract}
ABSTRAK
Semakin banyak bisnis di Indonesia saat ini yang mengadopsi internet dalam melakukan pemasaran dan penjualan produk. Persaingan antar produk di pasaran mendorong produsen berpromosi melalui iklan online. Online Behavioral Advertising (OBA) adalah praktik menyesuaikan iklan berdasarkan aktivitas online individu seperti mencari kata kunci dan mengunjungi situs web. Tujuan dari penelitian ini adalah untuk mengembangkan model konseptual untuk OBA dan menguji pengaruh kepercayaan konsumen pada penerimaan OBA. Dengan menggunakan data dari 100 responden yang merupakan karyawan PT. Erajaya Swasembada, Tbk Jakarta, hubungan yang dihipotesiskan diuji dengan Structural Equation Modeling. Hasil penelitian menunjukkan bahwa terdapat pengaruh OBA terhadap intention to click $O B A$ melalui mediasi attitude toward $O B A$. Hasil penelitian juga menunjukkan bahwa perceived informativeness, perceived credibility, perceived personalization, perceived interactivity memiliki pengaruh terhadap intention to click OBA melalui mediasi attitude toward OBA. Namun perceived entertainment tidak berpengaruh terhadap intention to click OBA melalui mediasi attitude toward OBA. Menurut hasil penelitian consumer trust memiliki pengaruh terhadap intention to click OBA. Implikasi untuk praktik manajemen dan penelitian selanjutnya juga dibahas dalam penelitian ini.
\end{abstract}

Kata Kunci: Online Behavioral Advertising, Consumer Trust, Attitude Toward OBA

\begin{abstract}
More and more businesses in Indonesia today are adopting the internet in marketing and selling products. Competition between products on the market encourages producers to promote through online advertising. Online Behavioral Advertising (OBA) is the practice of tailoring advertisements based on individual online activities such as searching for keywords and visiting websites. The purpose of this study is to develop a conceptual model for OBA and examine the effect of consumer confidence on OBA acceptance. By using data from 100 respondents who are employees of PT. Erajaya Swasembada, Tbk Jakarta, the hypothesized relationship was tested with Structural Equation Modeling. The results showed that there was an influence of OBA on intention to click OBA through mediating attitude towards OBA. The results also showed that perceived informativeness, perceived credibility, perceived personalization, perceived interactivity had an influence on OBA intention to click through mediating attitude toward OBA. But perceived entertainment does not affect the intention to click OBA through mediating attitude towards OBA. According to the results of consumer trust research has an influence on OBA's intention to click. Implications for future management and research practices are also discussed in this study.
\end{abstract}

Keywords: Online Behavioral Advertising, Consumer Trust, Attitude Toward OBA

\section{PENDAHULUAN}

\section{Latar Belakang}

Meningkatnya jumlah pengguna internet saat ini membawa kesempatan yang menjanjikan bagi sektor bisnis. Hal ini dapat dilihat bahwa semakin banyak sektor bisnis yang menggunakan media digital, terutama dalam strategi pemasaran. Peluang bisnis yang menjanjikan di internet merangsang munculnya berbagai ritel online atau yang kerap dikenal sebagai $e$-commerce.

Dengan tingginya persaingan dalam dunia bisnis ini akan menuntut perusahaan untuk lebih kreatif dan memiliki keunggulan kompetitif. Agar dapat bertahan dalam ekonomi global yang 
sangat kompetitif, bisnis harus memanfaatkan teknologi bank data dan analisis data untuk mengumpulkan informasi pelanggan, menganalisis karakteristik dan perilaku mereka, membangun hubungan dengan pelanggan yang sudah ada, dan menarik calon pelanggan.

Pengiklan online dirasa perlu mengkolaborasikan informasi pribadi konsumen dengan web history seseorang dalam rangka membuat profil yang sesuai dengan karakteristik dan kemungkinan minat seseorang lalu menempatkan iklan tersebut secara langsung pada orang yang dituju (McDonald \& Cranor, 2010). Iklan online seperti ini disebut Online Behavioural Advertising. Pada mekanisme OBA penyedia produk dan jasa tidak hanya menyampaikan iklan kepada konsumen, namun juga memberikan bantuan kepada konsumen untuk mendapatkan informasi yang lebih baik tentang produk maupun jasa yang sesuai dengan minat dan ketertarikannya.

Penerapan OBA juga menimbulkan dilema bagi konsumen, dimana pengembangan layanan yang lebih dipersonalisasi dan disesuaikan mengakibatkan penggunaan informasi pribadi konsumen tidak dapat dihidari sehingga akan menimbulkan masalah privasi konsumen yang berakibat pada kepercayaan konsumen pada iklan OBA.

Salah satu industri yang mengharapkan efek kuat OBA adalah retail. Globalisasi industri retail telah dipercepat dengan kemajuan teknologi dan komunikasi. Adanya pergeseran aktivitas berbelanja dari konsumen harus merasakan atau mencoba sendiri barang yang akan mereka beli menjadi aktivitas yang hanya cukup dengan memainkan jari tangan di perangkat mobile atau komputer yang dimiliki konsumen membuat peran OBA sangat penting saat ini.

PT. Erajaya Swasembada, Tbk adalah perusahaan retail perangkat elektronik yang berhubungan dengan telekomunikasi. Penjualan retail berbasis e-commerce dilakukan pada Erafone Dotcom, iBox.co.id dan Mii.com. Penerapan OBA sangat penting di awal perkembangan bisnis $e$ commerce tersebut. Pentingnya dilakukan penelitian ini agar hasilnya dapat dijadikan sebagai acuan dalam menentukan strategi beriklan dengan menggunakan OBA pada bisnis e-commerce di PT. Erajaya Swasembada, Tbk.

Berdasarkan uraian tersebut untuk mengetahui secara jelas seberapa besar pengaruh dari penerapan OBA terhadap sikap konsumen dan untuk mengembangkan beberapa penelitian terdahulu mengenai tanggapan konsumen terhadap OBA maka sangat menarik untuk mengambil topik penelitian mengenai pengaruh online behavioural advertising dan consumer trust pada sikap dan niat konsumen merespon online advertising.

\section{Rumusan Masalah}

Berdasarkan latar belakang di atas, maka dapat dirumuskan masalah penelitian sebagai berikut: Apakah OBA berpengaruh terhadap intention to click OBA yang dimediasi oleh attitude toward OBA pada karyawan PT. Erajaya Swasembada, Tbk di Jakarta? dan Apakah consumer trust berpengaruh terhadap intention to click OBA pada karyawan PT. Erajaya Swasembada, Tbk di Jakarta?

\section{METODE PENELITIAN}

Jenis penelitian yang digunakan adalah penelitian kuantitatif dengan pendekatan deskriptif. Dilihat dari permasalahan yang diteliti, penelitian ini merupakan penelitian kausalitas, yang bertujuan untuk menganalisis hubungan dan pengaruh dari dua atau lebih fenomena melalui pengujian hipotesis (Sekaran, 2003). Penelitian ini hanya dilaksanakan satu kali, sehingga 
dimensi waktu penelitiannya adalah cross-sectional/one-shot studies (Sekaran, 2003). Penelitian dilakukan dalam kurun waktu 7 bulan, yaitu dari Agustus 2018 hingga Maret 2019.

Jumlah Populasi dalam penelitian ini adalah 1042 karyawan yang bekerja di PT. Erajaya Swasembada, Tbk Jakarta. Populasi pada penelitian ini dipersempit dengan menghitung ukuran sampel yang dilakukan berdasarkan teknik Slovin menurut Sugiyono (2013). Sampel yang menjadi responden disesuaikan menjadi sebanyak 100 orang, agar mempermudah dalam pengolahan data dan untuk hasil pengujian yang lebih baik.

Sumber data dalam penelitian ini menggunakan data primer dan data sekunder. Data primer yang ada dalam penelitian ini berasal dari penyebaran kuesioner, sedangkan data sekunder diperoleh dari jurnal penelitian sebelumnya yang mendukung serta diperoleh dengan melakukan penelitian kepustakaan (library research). Jenis data yang digunakan adalah data kuantitatif, dimana metode pengumpulan data menggunakan kuesioner. Pengukuran variabel dilakukan dengan menggunakan skala likert.

Variabel penelitian terdiri dari tiga macam variabel, yaitu variabel bebas (independent variable), variabel terikat (dependent variable), serta variabel mediasi (intervening variable). Variabel independent dalam penelitian ini adalah OBA yang memiliki dimensi antara lain entertainment, informativeness, credibility, personalization, interactivity dan variabel consumer trust. Variabel dependent dalam penelitian ini adalah intention to click OBA. Variabel intervening dalam penelitian ini adalah attitude toward OBA. Teknik analisis data yang digunakan dalam penelitian ini adalah analisis kuantitatif dengan pendekatan Structural Equation Model (SEM) melalui software Smart Partial Least Square 3.0.

Model Ducoffe adalah perwakilan dari teori yang menjelaskan efek iklan online (Jin Lee et al., 2013). Namun hal tersebut tidak mencerminkan perbedaan karakteristik OBA, keunggulan dari penargetan individu, dan tidak dapat menjelaskan pengaruh sikap terhadap iklan pada perilaku konsumen. Oleh karena itu studi ini mengusulkan kemungkinan hubungan antara konstruk yang terkait dengan dimensi persepsi OBA, sikap terhadap OBA, kepercayaan konsumen, dan niat untuk mengeklik OBA.

Model penelitian dan hipotesis yang digunakan pada penelitian ini ditunjukkan dalam Gambar 1. 


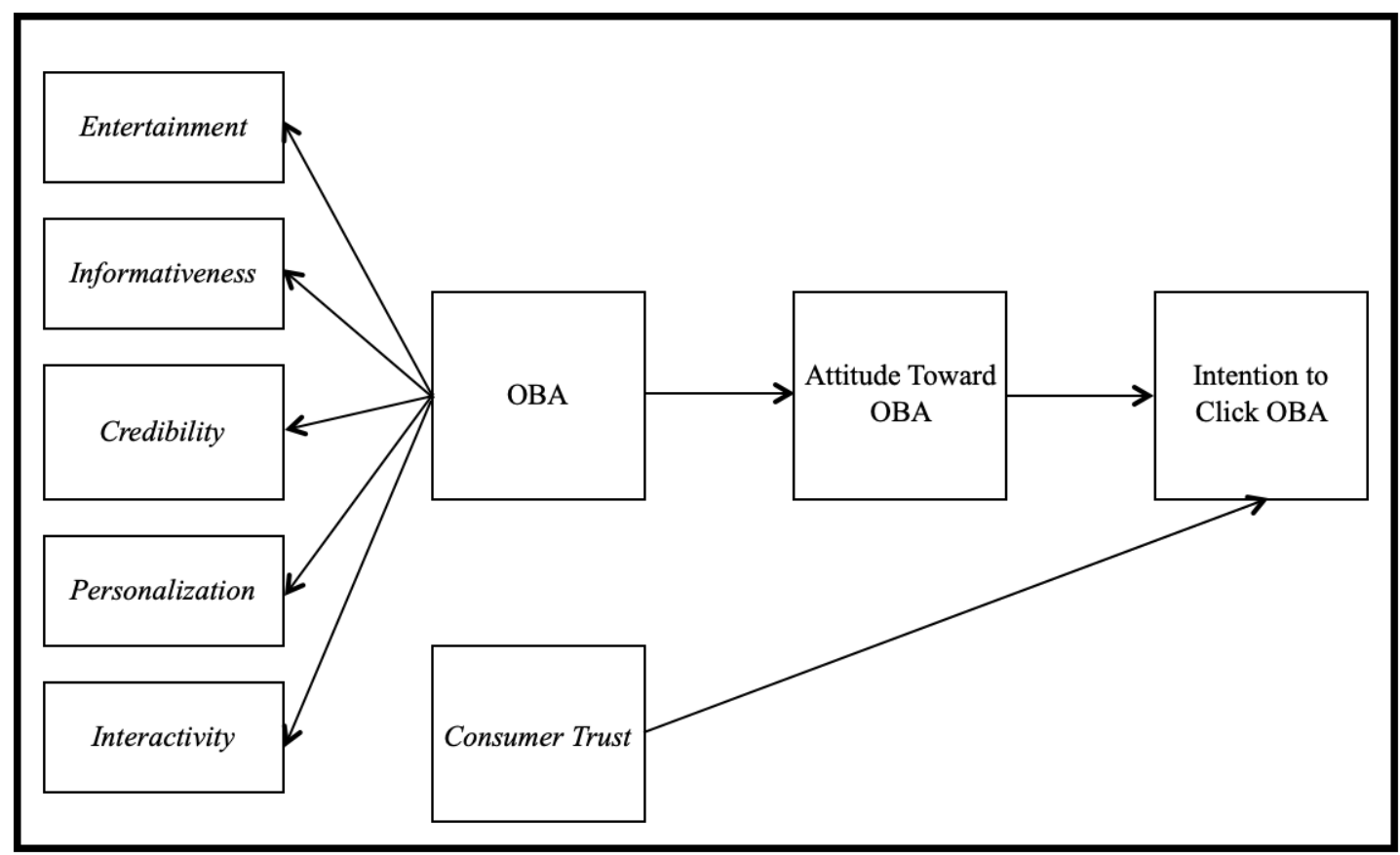

Gambar 1. Model Penelitian

\section{Entertainment}

Salah satu keunggulan paling menonjol dari iklan online adalah kemampuannya untuk memberikan hiburan kepada konsumen. McDonald dan Cranor (2010) juga menyarankan agar konsumen mengenali hiburan sebagai keuntungan OBA.

\section{Informativeness}

Internet dapat memberikan nilai informasi yang lebih besar karena memungkinkan akses langsung ke informasi dibandingkan dengan media tradisional (Jin Lee et al., 2013). Karena konsumen bukan penerima pasif online tetapi lebih memilih dan menggunakan informasi yang diperlukan melalui mengeklik, seberapa efisien suatu situs memuaskan keinginan informasi konsumen dapat menjadi faktor utama yang menentukan sikap terhadap iklan (Rodgers \& Thorson, 2000).

\section{Credibility}

Credibility pada iklan online ialah bagaimana tingkat kepercayaan konsumen terhadap iklan online yang muncul atau sejauh mana iklan memberikan informasi pada mereka dapat dipercaya, tidak memihak, kompeten, kredibel dan khusus. Credibility iklan telah terbukti sebagai faktor penting yang memengaruhi iklan di internet Jin Lee et al., 2013).

\section{Personalization}

Personalization meningkatkan kemungkinan bahwa konsumen akan menemukan sesuatu yang mereka inginkan (Jin Lee et al., 2013). Konsumen menunjukkan sikap yang lebih baik terhadap iklan dan produk target iklan jika iklan tersebut terkait dengan mereka.

\section{Interactivity}

Inti dari interactivity adalah untuk bertukar informasi antara konsumen dan penyedia iklan. Interactivity iklan bertujuan untuk mengubah persepsi atau perilaku konsumen melalui tindakan dan tanggapan dari reaksi. Interactivity mendorong perlunya informasi, yang pada akhirnya akan mempengaruhi sikap terhadap iklan.

\section{Consumer Trust}

Kepercayaan dapat didefinisikan sebagai perasaan aman dan kemauan untuk bergantung pada seseorang atau sesuatu. Karena kebanyakan orang tidak tahu apakah informasi mereka 
dikumpulkan, direkam, dan mungkin digunakan untuk tujuan yang tidak diinginkan, mereka menjadi semakin sadar tentang bagaimana informasi mereka digunakan (Kim et al., 2011).

\section{Attitude Toward OBA dan Intention to Click OBA}

Sikap terhadap iklan didefinisikan sebagai pra-disposisi untuk merespons dengan cara yang menguntungkan atau tidak menguntungkan terhadap stimulus periklanan tertentu selama adanya kesempatan. Tidak seperti media tradisional, konsumen dapat secara aktif berinteraksi dengan iklan online tergantung pada pilihan mereka sendiri. Penting untuk melibatkan perhatian selektif konsumen dengan meningkatkan perilaku mengeklik iklan (Jin Lee et al., 2013).

\section{Hipotesis Penelitian}

$\mathrm{H} 1$ : OBA mempunyai pengaruh positif terhadap intention to click OBA melalui mediasi attitude toward OBA.

$\mathrm{H} 2$ : Consumer Trust mempunyai pengaruh positif secara langsung terhadap intention to click OBA.

Variabel penelitian, indikator dan sumber yang dijadikan acuan dalam mengadopsi variabel dalam penelitian ini dapat dilihat pada tabel 1.

Tabel 1. Variabel dan Indikator Penelitian

\begin{tabular}{|c|c|c|}
\hline Variabel & Indikator & Sumber \\
\hline Entertainment & $\begin{array}{l}\text { a. Online Behavioral Advertising sangat menghibur } \\
\text { b. Online Behavioral Advertising sangat } \\
\text { menyenangkan }\end{array}$ & Ducoffe (1996) \\
\hline \multirow[t]{3}{*}{ Informativeness } & $\begin{array}{l}\text { c. Online Behavioral Advertising menarik } \\
\text { a. Online Behavioral Advertising adalah sumber } \\
\text { yang baik bagi informasi produk }\end{array}$ & Ducoffe (1996) \\
\hline & $\begin{array}{l}\text { b. Online Behavioral Advertising memberikan } \\
\text { informasi pada waktu yang tepat }\end{array}$ & \\
\hline & $\begin{array}{l}\text { c. Online Behavioral Advertising memberikan } \\
\text { informasi produk secara akurat }\end{array}$ & \\
\hline \multicolumn{3}{|c|}{ Tabel 1. Variabel dan Indikator Penelitian (lanjutan) } \\
\hline Variabel & Indikator & Sumber \\
\hline Credibility & $\begin{array}{l}\text { a. Saya menggunakan Online Behavioral } \\
\text { Advertising sebagai referensi untuk melakukan } \\
\text { pembelian } \\
\text { b. Saya percaya pada Online Behavioral } \\
\text { Advertising } \\
\text { c. Konten yang disediakan oleh Online Behavioral } \\
\text { Advertising dapat dipercaya }\end{array}$ & $\mathrm{Xu}(2007)$ \\
\hline \multirow[t]{3}{*}{ Personalization } & $\begin{array}{l}\text { anline Behavioral Advertising menyediakan } \\
\text { iklan yang disesuaikan dengan selera saya }\end{array}$ & $\begin{array}{l}\text { Srinivasan et al. } \\
(2002)\end{array}$ \\
\hline & $\begin{array}{l}\text { b. Online Behavioral Advertising menyediakan } \\
\text { iklan yang disesuaikan dengan kebutuhan saya }\end{array}$ & \\
\hline & $\begin{array}{l}\text { c. Online Behavioral Advertising menyediakan } \\
\text { iklan yang disesuaikan dengan situasi saya }\end{array}$ & \\
\hline Interactivity & $\begin{array}{l}\text { a. Saya selalu melihat dan menjadi penggemar } \\
\text { Online Behavioral Advertising yang saya sukai }\end{array}$ & $\begin{array}{l}\text { Tsang, Ho, \& } \\
\text { Liang (2004) }\end{array}$ \\
\hline
\end{tabular}




\begin{tabular}{|c|c|c|c|}
\hline \multirow[t]{3}{*}{ Consumer Trust } & a. & $\begin{array}{l}\text { Perusahaan online akan menggunakan informasi } \\
\text { pribadi saya secara jujur }\end{array}$ & \multirow[t]{3}{*}{$\begin{array}{l}\text { Eastlicket al. } \\
\text { (2006) }\end{array}$} \\
\hline & b. & $\begin{array}{l}\text { Perusahaan online akan mencurahkan lebih } \\
\text { banyak waktu dan upaya untuk menjaga } \\
\text { informasi pribadi saya }\end{array}$ & \\
\hline & c. & $\begin{array}{l}\text { Saya dapat mempercayai kebijakan kerahasiaan } \\
\text { data pribadi saya dari perusahaan online } \\
\text { sepenuhnya }\end{array}$ & \\
\hline $\begin{array}{l}\text { Intention to click } \\
\text { OBA }\end{array}$ & a. & $\begin{array}{l}\text { Saya bersedia untuk mengeklik dan memeriksa } \\
\text { isi online behavioural advertising tentang produk } \\
\text { yang ditawarkan }\end{array}$ & $\begin{array}{l}\text { Wixom \& Todd } \\
\text { (2005) }\end{array}$ \\
\hline \multirow[t]{3}{*}{$\begin{array}{l}\text { Attitude Toward } \\
\text { OBA }\end{array}$} & a. & $\begin{array}{l}\text { Memanfaatkan Online Behavioral Advertising } \\
\text { sangat menyenangkan }\end{array}$ & \multirow[t]{3}{*}{$\begin{array}{l}\text { Wixom \& Todd } \\
\text { (2005) }\end{array}$} \\
\hline & b. & $\begin{array}{l}\text { Secara keseluruhan, menggunakan Online } \\
\text { Behavioral Advertising adalah pengalaman yang } \\
\text { menyenangkan }\end{array}$ & \\
\hline & c. & $\begin{array}{l}\text { Saya merasa Online Behavioral Advertising } \\
\text { sangat menguntungkan ketika saya gunakan }\end{array}$ & \\
\hline
\end{tabular}

\section{HASIL DAN PEMBAHASAN}

Deskripsi Responden

Responden dalam penelitian ini sangat beragam, baik dari divisi kerja, jenis kelamin, umur, pendidikan, domisili, uang saku dan/atau penghasilan, intensitas berbelanja online, durasi beraktivitas online per hari dan alasan tertarik berbelanja online. Pengelompokkan responden berdasarkan karakteristiknya ditunjukkan oleh tabel 2 .

Tabel 2. Karakteristik Responden Sumber: Hasil Pengolahan Data

\begin{tabular}{clc}
\hline \multicolumn{1}{c}{ Characteristics } & Classification & Percentage (\%) \\
\hline Divisi Kerja & Finance & $75 \%$ \\
& Accounting \& Tax & $12 \%$ \\
& Sales & $8 \%$ \\
& Marketing Communication & $2 \%$ \\
& Strategic Planning & $2 \%$ \\
& HR \& GA & $1 \%$ \\
Jenis Kelamin & Pria & $46 \%$ \\
Umur & Wanita & $54 \%$ \\
& $16-20$ tahun & $0 \%$ \\
& $21-25$ tahun & $22 \%$ \\
& $26-30$ tahun & $52 \%$ \\
& $31-35$ tahun & $20 \%$ \\
Pendidikan & $36-40$ tahun & $3 \%$ \\
& $\geq 41$ tahun & $3 \%$ \\
& SMA / Setara & $9 \%$
\end{tabular}




\begin{tabular}{|c|c|c|}
\hline & D1 - D3 & $9 \%$ \\
\hline & $\mathrm{S} 1$ & $77 \%$ \\
\hline & $\mathrm{S} 2$ & $5 \%$ \\
\hline \multirow[t]{5}{*}{ Domisili } & Jakarta Barat & $38 \%$ \\
\hline & Jakarta Utara & $19 \%$ \\
\hline & Jakarta Timur & $18 \%$ \\
\hline & Jakarta Pusat & $15 \%$ \\
\hline & Jakarta Selatan & $10 \%$ \\
\hline Uang Saku dan/atau & $<\operatorname{Rp} 1.000 .000-\operatorname{Rp} 3.000 .000$ & $0 \%$ \\
\hline \multirow[t]{4}{*}{ Penghasilan } & $>\operatorname{Rp} 3.000 .000-\operatorname{Rp} 5.000 .000$ & $38 \%$ \\
\hline & $>\operatorname{Rp} 5.000 .000-\operatorname{Rp} 7.000 .000$ & $24 \%$ \\
\hline & > Rp 7.000.000 - Rp 9.000.000 & $10 \%$ \\
\hline & $>\operatorname{Rp} 9.000 .000$ & $28 \%$ \\
\hline Intensitas Berbelanja & $\leq 1 \mathrm{kali}$ & $14 \%$ \\
\hline \multirow[t]{4}{*}{ Online } & $\geq 5 \mathrm{kali}$ & $56 \%$ \\
\hline & 2 kali & $9 \%$ \\
\hline & 3 kali & $16 \%$ \\
\hline & 4 kali & $5 \%$ \\
\hline Durasi Beraktivitas & 1 jam & $30 \%$ \\
\hline \multirow[t]{4}{*}{ Online Per hari } & $2-3$ jam & $30 \%$ \\
\hline & $4-5$ jam & $15 \%$ \\
\hline & $6-7$ jam & $8 \%$ \\
\hline & $>7$ jam & $17 \%$ \\
\hline \multicolumn{3}{|c|}{ Tabel 2. Karakteristik Responden (lanjutan) } \\
\hline Characteristics & Classification & Percentage $(\%)$ \\
\hline Alasan Tertarik & Tertarik dengan promo yang ditawarkan & $34 \%$ \\
\hline \multirow[t]{4}{*}{ Berbelanja Online } & Kemudahan bertransaksi & $27 \%$ \\
\hline & $\begin{array}{l}\text { Produk yang diinginkan tidak tersedia di toko } \\
\text { konvensional }\end{array}$ & $11 \%$ \\
\hline & $\begin{array}{l}\text { Diajak / direkomendasikan oleh keluarga / } \\
\text { teman }\end{array}$ & $3 \%$ \\
\hline & Menghemat waktu dan tenaga & $25 \%$ \\
\hline
\end{tabular}

\section{Evaluasi Model Pengukuran (Outer Model)}

Berdasarkan sajian data dalam tabel 3, diketahui bahwa masing-masing indikator variabel penelitian banyak yang memiliki nilai loading factor $>0,6$. Namun, terlihat masih terdapat beberapa indikator yang memiliki nilai loading factor $<0,6$. Menurut Chin seperti yang dikutip oleh Imam Ghozali, nilai loading factor antara 0,5 - 0,6 sudah dianggap cukup untuk memenuhi syarat convergent validity. Nilai AVE atas constructs OBA, entertainment, informativeness, credibility, personalization, interactivity, consumer trust, intention to click OBA dan attitude toward OBA > 0,5. Dengan demikian dapat dinyatakan bahwa setiap constructs telah memiliki convergen validity yang baik.

Pada tabel 3 juga dapat diketahui bahwa nilai cronbach alpha dari masing-masing variabel penelitian > 0.7. Dengan demikian hasil ini dapat menunjukkan bahwa masing-masing variabel 
penelitian telah memenuhi persyaratan nilai cronbach alpha, sehingga dapat disimpulkan bahwa keseluruhan variabel memiliki tingkat reliabilitas yang tinggi. Pada penelitian ini, nilai composite reliability semua variabel penelitian $>0,7$. Hasil ini menunjukkan bahwa masingmasing variabel telah memenuhi composite realibility sehingga dapat disimpulkan bahwa keseluruhan variabel memiliki tingkat realibilitas yang tinggi.

Suatu variabel dapat dinyatakan lulus uji multikolinearitas apabila memiliki nilai VIF (Variance Inflation Factor) < 10. Berdasarkan pengolahan data yang telah dilakukan dengan menggunakan program Smart PLS 3.0, diperoleh nilai VIF untuk variabel OBA, Attitude Toward OBA dan Consumer Trust masing-masing adalah sebesar 1,0;1,44 dan 1,44. Hasil ini menunjukkan bahwa masing-masing variabel telah lulus uji multikolinearitas. Sehingga hasil pengujian ini dapat dilanjutkan ke tahap berikutnya.

Tabel 3. Hasil Convergent Validity dan Uji Reliabilitas

Sumber: Hasil Pengolahan Data

\begin{tabular}{lccccc}
\hline \multicolumn{1}{c}{ Constructs } & \multicolumn{3}{c}{ Convergent Validity } & \multicolumn{2}{c}{ Uji Realibilitas } \\
& Items & $\begin{array}{c}\text { Loading } \\
\text { Factor }\end{array}$ & AVE & Alphach & $\begin{array}{c}\text { Composite } \\
\text { Reliability }\end{array}$ \\
\hline Entertainment & ENT1 & 0,7482 & 0,8555 & 0,9148 & 0,9466 \\
& ENT2 & 0,7803 & & & \\
& ENT3 & 0,7174 & & & 0,8799 \\
\hline Informativeness & INF1 & 0,6249 & 0,7100 & & \\
& INF2 & 0,7447 & & & \\
& INF3 & 0,6314 & & & \\
\hline
\end{tabular}

Tabel 3. Hasil Convergent Validity dan Uji Reliabilitas (lanjutan)

\begin{tabular}{|c|c|c|c|c|c|}
\hline \multirow[b]{2}{*}{ Constructs } & \multirow[b]{2}{*}{ Items } & \multicolumn{2}{|c|}{ Convergent Validity } & \multicolumn{2}{|c|}{ Uji Realibilitas } \\
\hline & & $\begin{array}{c}\text { Loading } \\
\text { Factor }\end{array}$ & AVE & $\begin{array}{l}\text { Cronbach } \\
\quad \text { Alpha }\end{array}$ & $\begin{array}{l}\text { Composite } \\
\text { Reliability }\end{array}$ \\
\hline \multirow[t]{3}{*}{ Credibility } & CRD1 & 0,7549 & 0,6839 & 0,7645 & 0,8655 \\
\hline & CRD2 & 0,7907 & & & \\
\hline & CRD3 & 0,6203 & & & \\
\hline \multirow[t]{3}{*}{ Personalization } & PER1 & 0,5334 & 0,7478 & 0,8355 & 0,8985 \\
\hline & PER2 & 0,7205 & & & \\
\hline & PER3 & 0,7350 & & & \\
\hline \multirow[t]{2}{*}{ Interactivity } & INT1 & 0,7775 & 0,9019 & 0,8918 & 0,9484 \\
\hline & INT2 & 0,7751 & & & \\
\hline \multirow{3}{*}{ Consumer Trust } & TRS1 & 0,9126 & 0,8592 & 0,9181 & 0,9482 \\
\hline & TRS2 & 0,9313 & & & \\
\hline & TRS3 & 0,9367 & & & \\
\hline \multirow[t]{3}{*}{ Attitude Toward OBA } & ATT1 & 0,9268 & 0,8309 & 0,8982 & 0,9365 \\
\hline & ATT2 & 0,9156 & & & \\
\hline & ATT3 & 0,8919 & & & \\
\hline Intention to Click OBA & IOBA & 1,0000 & 1,0000 & 1,0000 & 1,0000 \\
\hline OBA & & & 0,5112 & 0,9258 & 0,9354 \\
\hline
\end{tabular}




\section{Evaluasi Model Struktural (Inner Model)}

Pengujian terhadap model struktural dilakukan dengan cara melihat nilai $R$-Square $\left(\mathrm{R}^{2}\right)$. Berdasarkan pengolahan data yang telah dilakukan dengan menggunakan program Smart PLS 3.0, diperoleh nilai $R$-Square $\left(\mathrm{R}^{2}\right)$ untuk variabel attitude toward OBA adalah 0,6093. Perolehan nilai tersebut menjelaskan bahwa variabel OBA secara simultan mampu menjelaskan pengaruhnya terhadap variabel attitude toward OBA sebesar 60,93\% sedangkan 39,07\% dijelaskan oleh variabel lain di luar model yang diteliti. Nilai $R$-Square untuk variabel intention to click OBA adalah 0,5308. Hal ini berarti variabel consumer trust dan variabel attitude toward OBA secara simultan mampu menjelaskan pengaruhnya terhadap variabel intention to click OBA sebesar 53,08\% sedangkan 46,92\% dijelaskan oleh variabel lain di luar model yang diteliti.

\section{Uji Hipotesis}

Dalam menguji hipotesis, penelitian ini menggunakan beberapa kriteria yang harus dipenuhi, yaitu $t$-statistics, dan $p$-values. Nilai $t$-statistics dan $p$-values digunakan untuk menunjukan signifikansi. Dalam penelitian ini nilai $t$-statistics yang harus dicapai agar suatu hipotesis dapat diterima adalah $>1,64$, sedangkan nilai $p$-values yang harus dicapai agar suatu hipotesis dapat diterima adalah $<5 \%$ atau $<0,05$.

Berdasarkan hasil pengujian hipotesis pertama dapat disimpulkan bahwa variabel OBA berpengaruh positif terhadap intention to click OBA melalui mediasi attitude toward OBA. Pada OBA terhadap attitude toward OBA terdapat nilai p-values sebesar 0,0000 $(<0,05)$ dengan nilai $t$-statistics sebesar 20,7260 (>1,64) dan pada attitude toward OBA terhadap intention to click OBA terdapat nilai $p$-values sebesar $0,0000(<0,05)$ dengan nilai $t$-statistics sebesar 8,7018 (> 1,64). Hal ini menunjukkan bahwa terdapat pengaruh positif antara OBA terhadap intention to click OBA melalui mediasi attitude toward OBA. Responden dalam penelitian ini memiliki niat untuk mengeklik OBA karena pengaruh dari sikap terhadap iklan online yang diterima.

Dari hasil uji hipotesis hubungan antara consumer trust terhadap intention to click, menunjukan bahwa nilai $t$-statistics adalah sebesar 1,2456 atau $<1,64$, dengan nilai $p$-values sebesar 0,2135 atau $>0,05$. Kedua kriteria uji hipotesis tidak terpenuhi, sehingga hipotesis H2 tidak diterima, maka dapat dikatakan bahwa consumer trust tidak mempunyai pengaruh positif secara langsung terhadap intention to click OBA. Konsumen yang telah memiliki kepercayaan pada perusahaan online dan bahkan ketika konsumen tersebut sudah pernah melakukan pembelian, hal tersebut tidak menjadi dasar bagi konsumen untuk mengeklik OBA.

Hasil uji hipotesis $\mathrm{H} 1$ dan $\mathrm{H} 2$ juga dapat dilihat pada tabel 4.

Tabel 4. Hasil Uji Hipotesis

Sumber: Hasil Pengolahan Data

\begin{tabular}{|c|c|c|c|c|}
\hline Pengaruh & T-Statistics & P-Values & Keputusan & Kesimpulan \\
\hline $\begin{array}{l}\text { OBA } \Rightarrow>\text { Attitude Toward } \\
\text { OBA }\end{array}$ & 20,726 & 0,0000 & Terima $\mathrm{H}_{1}$ & $\begin{array}{l}\text { Berpengaruh } \\
\text { Signifikan }\end{array}$ \\
\hline $\begin{array}{l}\text { Attitude Toward } \mathrm{OBA}=> \\
\text { Intention to Click OBA }\end{array}$ & 8,7018 & 0,0000 & Terima $\mathrm{H}_{1}$ & $\begin{array}{l}\text { Berpengaruh } \\
\text { Signifikan }\end{array}$ \\
\hline $\begin{array}{l}\text { Consumer Trust => Intention } \\
\text { to Click OBA }\end{array}$ & 1,2456 & 0,1800 & Tolak $\mathrm{H}_{0}$ & $\begin{array}{l}\text { Tidak Berpengaruh } \\
\text { Signifikan }\end{array}$ \\
\hline
\end{tabular}




\section{KESIMPULAN DAN SARAN}

\section{Kesimpulan}

Berdasarkan penelitian tentang pengaruh online behavioural advertising dan consumer trust pada sikap dan niat konsumen merespon online advertising, maka diperoleh kesimpulan sebagai berikut:

\section{Pengaruh OBA terhadap intention to click OBA melalui mediasi attitude toward OBA}

Terdapat pengaruh OBA terhadap intention to click OBA melalui mediasi attitude toward OBA. Hasil penelitian ini mendukung hasil penelitian sebelumnya yang dilakukan oleh Jin Lee et al (2013) yang menyatakan bahwa attitude toward OBA berhubungan positif dengan intention to click tourism OBA. Penelitian sebelumnya yang dilakukan oleh Sevtap Ünal et al (2011), juga didukung oleh hasil penelitian ini.

\section{Pengaruh consumer trust terhadap intention to click OBA}

Tidak terdapat hubungan atau pengaruh langsung dari consumer trust terhadap intention to click OBA. Konsumen yang telah memiliki kepercayaan pada perusahaan online dan bahkan ketika konsumen tersebut sudah pernah melakukan pembelian, hal tersebut tidak menjadi dasar bagi konsumen untuk mengeklik OBA. Hal tersebut dikarenakan beberapa konsumen cenderung mempertimbangkan kembali iklan online tersebut atau seringkali konsumen lebih memilih untuk membuka web/aplikasi yang berkaitan dengan iklan online tersebut tanpa mengekliknya. Hasil penelitian ini tidak mendukung penelitian sebelumnya oleh Jin Lee et al (2013).

\section{Saran}

Penelitian ini masih mengandung banyak kekurangan dalam pelaksanaannya, sehingga peneliti memberikan saran-saran yang bersifat teoritis agar pada penelitian selanjutnya, kekurangankekurangan yang ada dapat dihindari dan menjadi penelitian yang lebih baik. Saran teoritis yang diberikan antara lain:

(i) penelitian selanjutnya dapat memperhatikan perbedaan antar jenis produk yang diiklankan,

(ii) penelitian selanjutnya dapat mempertimbangkan untuk menambahkan dimensi persepsi OBA yang lain,

(iii) penelitian selanjutnya perlu mempertimbangkan perbedaan budaya atau negara tertentu dalam reaksi konsumen terhadap OBA,

(iv) penelitian selanjutnya perlu mempertimbangkan untuk menambah metode wawancara agar hasil penelitian yang diperoleh akan lebih lengkap, dan

(v) sampel pada penelitian selanjutnya dapat ditambah agar hasil penelitian dapat digeneralisasikan dalam lingkup yang lebih luas.

\section{Ucapan Terima Kasih}

Penelitian ini tidak akan terwujud tanpa adanya bantuan dan dorongan dari berbagai pihak. Sehingga ucapan terima kasih sangat perlu diucapkan kepada pihak-pihak tersebut, antara lain Ibu Dr. Hetty Karunia Tunjungsari, S.E., M.Si.; Bapak Hardius Usman, S.Si., M.Si.; dan kepada keluarga serta teman-teman yang terus mendukung hingga terselesainya penelitian ini.

\section{REFERENSI}

Jin Myung, Lee and Rha, Jong Youn. (2013). The Effect of Privacy Concerns and Consumer Trust on Consumer Response to Online Behavioral Advertising for Travel Products. International Journal of Tourism Sciences, 13 (3), 1-29.

Kwon, Kwiseok; Cookhwan Kim. (2011). "How to Design Personalization in a Context of Customer Retention : Who Personalizes and to What Extent?". Electronic Commerce Research and Application. 11:101-116. 
Latan. H. dan Ghozali. I. (2012). Partial Least Squares Konsep. Teknik dan Aplikasi Menggunakan Program SmartPLS 2.0 M3. Semarang: Badan Penerbit Universitas Diponegoro.

Ma. Yuanxin and Pittana. Noichangkid. (2016). Bored with Ads: A Study Investigating Attitude towards Social Media Advertising. Master Thesis. Umeå School of Business.

McDonald, Aleecia M and Cranor, Lorrie Faith. (2010). Americans' Attitudes About Internet Behavioral Advertising Practices. Workshop on Privacy in the Electronic Society, 10, 231241.

Rodgers, S., dan Thorson, E. (2000), "The Interactive Advertising Model: How Users Perceive and Process Online Ads," Journal of Interactive Advertising 1 (1), 26-50.

Sekaran, Uma. 2003. Research Methods for business: A Skill Building Approach. Singapore: John Wiley \& Sons, Inc.

Srinivasan, S. S., Anderson, R., and Ponnavolu, K. (2002). Customer Loyalty in E-commerce: An Exploration of its Antecedents And Consequences. Journal of Retailing, 78: 41-50.

Sugiyono. (2013). Metode Penelitian Pendidikan Pendekatan Kuantitatif. Kualitatif. dan R\&D. Bandung: Alfabeta.

Tsang, M. M., Ho, S. C., \& Liang, T.-P. (2004). Consumer Attitudes Toward Mobile Advertising: An Empirical Study. International Journal of Electronic Commerce, 8(3), 6578.

$\mathrm{Xu}$, David Jingjun. (2007). "The Influence of Personalization in Affecting Consumer Attitude toward Mobile Advertising in China". Journal of Computer Information Systems. 47(2): 919.

Wixom, B. H., \& Todd, P. A. (2005). A Theoretical Integration of User Satisfaction and Technology Acceptance. Information Systems Research, 16 (1), 85-102. 